\title{
OPEN Abrupt climate changes in the last two deglaciations simulated with different Northern ice sheet discharge and insolation
}

\begin{abstract}
Takashi Obase $^{1 \bowtie}$, Ayako Abe-Ouchi ${ }^{1,2}$ \& Fuyuki Saito ${ }^{3}$
There were significant differences between the last two deglaciations, particularly in Atlantic Meridional Overturning Circulation (AMOC) and Antarctic warming in the deglaciations and the following interglacials. Here, we present transient simulations of deglaciation using a coupled atmosphere-ocean general circulation model for the last two deglaciations focusing on the impact of ice sheet discharge on climate changes associated with the AMOC in the first part, and the sensitivity studies using a Northern Hemisphere ice sheet model in the second part. We show that a set of abrupt climate changes of the last deglaciation, including Bolling-Allerod warming, the Younger Dryas, and onset of the Holocene were simulated with gradual changes of both ice sheet discharge and radiative forcing. On the other hand, penultimate deglaciation, with the abrupt climate change only at the beginning of the last interglacial was simulated when the ice sheet discharge was greater than in the last deglaciation by a factor of 1.5. The results, together with Northern Hemisphere ice sheet model experiments suggest the importance of the transient climate and AMOC responses to the different orbital forcing conditions of the last two deglaciations, through the mechanisms of mass loss of the Northern Hemisphere ice sheet and meltwater influx to the ocean.
\end{abstract}

The climate system of the Earth underwent glacial-interglacial cycles associated with growth and decay of continental ice sheets, driven by insolation changes as the external forcing, and by climate system feedbacks. The transition from the glacial state to the interglacial state (deglaciation) typically occurred within about 10,000 years, characterized by global warming and melting of continental ice sheets ${ }^{1-3}$. Based on geological reconstructions from multiple lines of evidence, there were significant differences in the climate events of the last two deglaciations and the climate states of the following interglacials ${ }^{4}$. In particular, during the last deglaciation (glacial Termination 1, 19 to $11 \mathrm{ka} \mathrm{BP}$, hereafter referred to as T1), there was abrupt strengthening in the Atlantic Meridional Overturning Circulation (AMOC), which caused the Bolling-Allerod (BA) warming event during the middle stage $\mathrm{e}^{5,6}$. After the BA warming, the climate of the Antarctic region followed a cooling trend known as Antarctic Cold Reversal (ACR, 14.5 to $12.8 \mathrm{ka} \mathrm{BP}$ ), followed by the Younger Dryas (YD, 12.8 to $11.6 \mathrm{ka} \mathrm{BP}$ ), characterized by weakening in the AMOC and Antarctic warming until the onset of the present interglacial. In contrast, during the penultimate deglaciation (glacial Termination 2, 138 to $128 \mathrm{ka} \mathrm{BP}$, hereafter T2 $2^{4}$ ), the AMOC was weak for about 4000 years $(\sim 133$ to $129 \mathrm{ka} \mathrm{BP})$ during the middle and later stage of T2, followed by the strengthening of AMOC in the last interglacial (LIG, $\sim 129$ to $116 \mathrm{ka} \mathrm{BP})^{7-10}$. There were significant differences in the climate state of this interglacial compared with the present interglacial, as the sea surface temperature (SST) of the Southern Ocean and surface temperature over the Antarctic continent during the LIG were about $2^{\circ}$ higher than those of the present interglacial ${ }^{11}$. There were also differences in the global mean sea level, which was higher during the LIG than in the present by at least $5 \mathrm{~m}^{12-14}$, presumably because of mass loss of the West Antarctic Ice Sheet (WAIS) ${ }^{15,16}$. It has been noted that a weakened AMOC during the early LIG caused the Ant$\operatorname{arctic}_{\text {warmth }}{ }^{17,18}$ as the longer duration of weakened AMOC contributed to Antarctic warming ${ }^{19-22}$. Moreover, it has been hypothesized that greater boreal summer insolation caused faster retreat of Northern Hemisphere ice sheets and thus caused a weak AMOC throughout $\mathrm{T} 2^{8,9,23,24}$ based on the reconstructed sea level rise of T2, indicating that it was significantly faster than that of $\mathrm{T}^{8}$. Therefore, it is of importance to investigate the role

${ }^{1}$ Atmosphere and Ocean Research Institute, The University of Tokyo, 5-1-5, Kashiwanoha, Kashiwa, Chiba 277-8568, Japan. ${ }^{2}$ National Institute of Polar Research, Tachikawa, Japan. ${ }^{3}$ Japan Agency for Marine-Earth Science and Technology, Yokohama, Japan. ${ }^{\circledR}$ email: obase@aori.u-tokyo.ac.jp 
of orbital forcing on different climate events during the last two deglaciations through melting of Northern Hemisphere ice sheets and AMOC changes.

Transient simulations of the last deglaciation have been conducted using climate models, and climate events associated with variations in the AMOC have been represented by applying meltwater flux to the ocean ${ }^{25,26}$. Clark et al. ${ }^{27}$ conducted transient simulation of T2 using reconstructed climate forcing and greater meltwater flux than $\mathrm{T} 1$. They compared the results with the simulation of $\mathrm{T}^{25}$ and showed that the greater meltwater flux of T2 corresponding to Heinrich event 11 led to longer weakening in the AMOC and significant Antarctic warming that was sufficient to cause the mass loss of the WAIS. However, it is still unclear which phase of the deglaciation was important for the AMOC and Antarctic warming, and what the cause of significant ice sheet retreat during deglaciation was. Recently, abrupt AMOC recovery and associated ACR have been simulated with constant meltwater flux by transient simulation of the last deglaciation using the atmosphere-ocean coupled General Circulation Model (GCM) MIROC (Ref. ${ }^{28}$, hereafter OA2019).

In this study, first, we conducted sensitivity experiments of deglaciation with different levels of meltwater influencing the AMOC and surface temperature mainly over the Antarctic region, using an atmosphere-ocean coupled GCM. Second, we conducted sensitivity experiments of the effect of insolation on melting of the Northern Hemisphere ice sheets, using a three-dimensional Northern Hemisphere ice sheet model. We discuss the roles of orbital forcing and climate system feedbacks in the differences of the last two glacial terminations and the following interglacials.

\section{Results of transient climate model deglaciation experiments}

In this section, we describe the results of two deglaciation experiments. In Fig. 1, the reconstructions, experimental design and results from the two deglaciation experiments are compared by offsetting the age of T2 by $118 \mathrm{ka}$ to match the phases of deglacial climate changes, in the same manner as Clark et al. ${ }^{27}$. The simulation of T1 (T1-like experiment) is from OA2019 ${ }^{28}$, and was extended to $9 \mathrm{ka}$ BP to serve as a T1-like experiment covering the YD event and onset of the Holocene. In the sensitivity experiment to imitate T2 (T2-like experiment), we changed meltwater flux while maintaining identical orbital and atmospheric greenhouse gas forcings of T1 (Fig. 1a,b). In the T2-like experiment, about 1.5 times more meltwater was applied (Fig. 1c right side red lines), which roughly corresponded to the sea level rise rates of T1 and T2 during the middle stages of the deglaciations based on reconstructions (Fig. 1c left side shading). We used the ice sheet reconstructions ${ }^{29,30}$ of Ref. $^{31}$, and the sea level and meltwater based on ice-rafted debris ${ }^{32,33}$ of Ref. ${ }^{4}$. The values were carefully estimated so that the total amounts of applied meltwater in the two experiments did not exceed the amounts estimated from the reconstructions (Supplementary Fig. S1). We conducted several sensitivity experiments and found that the timing of AMOC changes was sensitive to the meltwater flux; a greater amount of meltwater tended to weaken the AMOC by reducing the sea surface salinity of the North Atlantic (Supplementary Fig. S2). We chose one experiment to serve as the T2-like experiment, which exhibited similar time series of the reconstructed AMOC and Antarctic air temperature of T2 (Refs. ${ }^{9,34}$; Fig. 1d-f). The time series of the simulated AMOC changes were compared with relative enrichment in heavy neodymium isotopes (Fig. 1d), which is a proxy of the relative influence of water mass from the North Atlantic Deep Water and Antarctic Bottom Water ${ }^{9,35}$, in the same manner as previous studies ${ }^{24,27}$.

In the T1-like experiment, an abrupt increase in the AMOC occurred (around $15 \mathrm{ka}$ ) in response to gradual warming even under continuous meltwater (Fig. 1d). As discussed in OA2019, this abrupt increase in the AMOC with gradual background climate change has been indicated by several climate models ${ }^{41-44}$. The exact mechanisms of the abrupt increase are still under investigation, but based on OA2019, the gradual warming tended to change the density of seawater, which is critical to the retreat of sea ice and recovery of deep water formation in the North Atlantic. The changes of the simulated Greenland temperatures in T1 and T2 closely matched the changes of the AMOC, consistent with atmospheric methane records (Fig. 1e), which represent climate changes in the Northern Hemisphere and methane sources and sinks ${ }^{39}$. The AMOC returned to a weak mode in response to increased meltwater during the YD, and reached a vigorous mode at the end of the YD (about $11.6 \mathrm{ka}$ BP, Fig. 1d). This reduction in $\mathrm{AMOC}$ in the YD can be simulated without reduction in meltwater, because of the oscillatory nature of the AMOC (Supplementary Fig. S2 pink lines). In contrast, in the T2-like experiment, the AMOC maintained a weak mode throughout the deglaciation until $128 \mathrm{ka} \mathrm{BP}$, as the larger amount of meltwater reduced the salinity and prevented deep convection in the North Atlantic. In Antarctica, there was cooling in the T1-like experiment in response to abrupt increase in the AMOC (15-13 ka in Fig. 1d,f), which closely corresponded to ACR. The duration or cooling of ACR tended to be shorter than reconstructions in previous deglaciation experiments with other climate models ${ }^{45}$, but in our simulation, the Antarctic cooling continued for about 2000 years until the onset of the YD event, as in reconstructions. In contrast, surface air temperature (SAT) around Antarctica continued warming in the T2-like experiment until $128 \mathrm{ka} \mathrm{BP}$, and the simulated peak in Antarctic SAT was higher than the interglacial level by about $2^{\circ}$ (Fig. 1f). The YD event associated with weakening of the AMOC in the T1-like experiment turned into an Antarctic warming trend for about 1300 years, but the Antarctic SAT did not reach the level of the T2-like experiment. Interestingly, a similar trend was found in the global mean ocean temperature, with a decrease during ACR of the last deglaciation and a maximum value during the onset of the LIG that was larger than the level of the Holocene ${ }^{24,40}$. These trends in global mean ocean temperature in response to the AMOC can be explained by subsurface and deep ocean temperature changes, which exhibited cooling after a recovery of the AMOC (Supplementary Fig. S3), as in previous climate modelling studies ${ }^{46-48}$. The response of the subsurface ocean to AMOC change was relatively rapid; the increase in the AMOC produced significant cooling within a few 100 years (Supplementary Fig. S4a,b black lines). The response of the deep-ocean was more gradual (Supplementary Fig. S4c). The amplitudes of simulated temperature changes from the glacial to the interglacial were smaller than those of reconstructions (Fig. 1f,g), because of the experimental design, wherein the ice sheet 

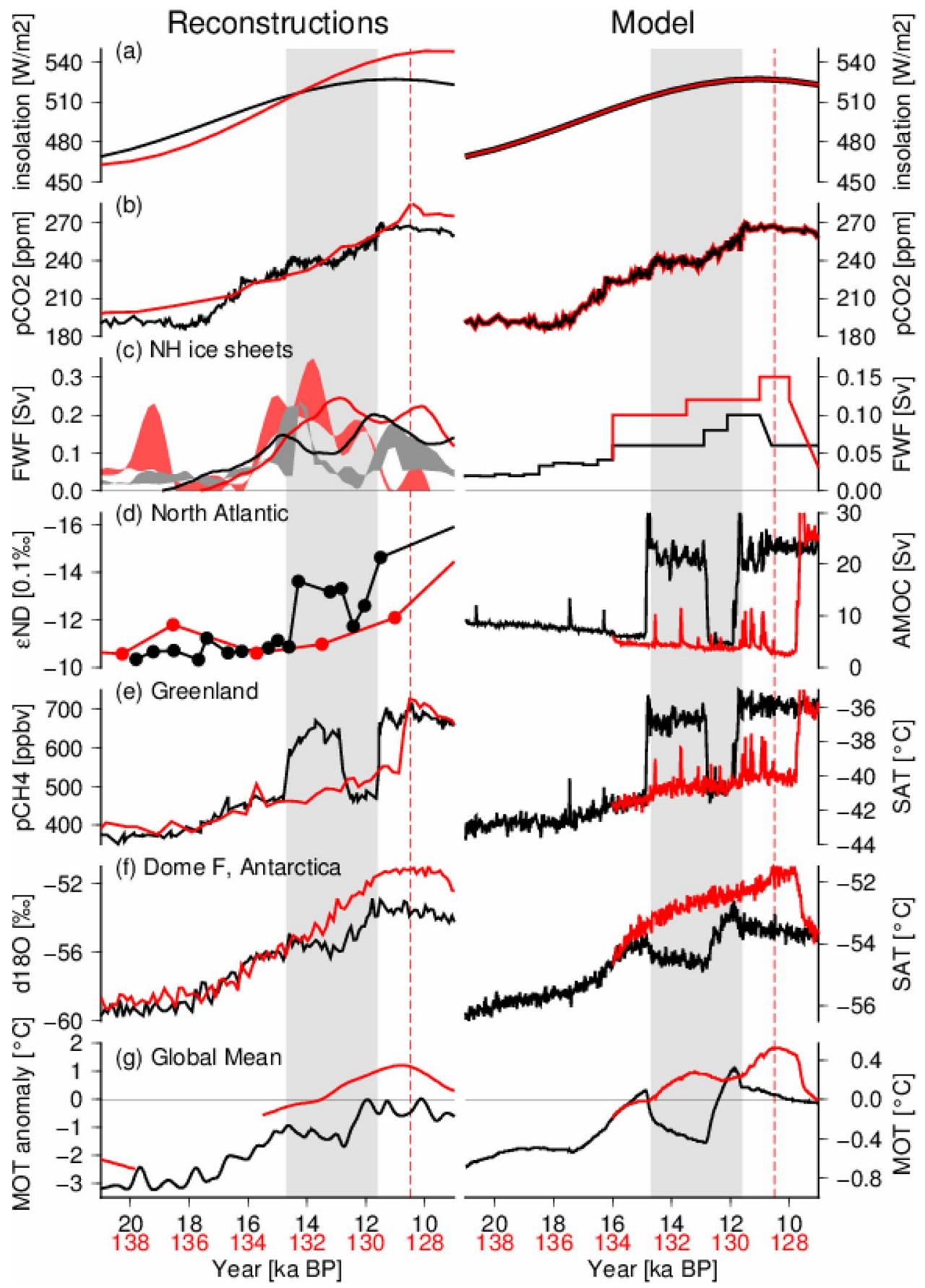

Figure 1. Climate model experimental design and results (right panels) compared with reconstructions (left panels). The black and red lines represent the last and penultimate deglaciations, respectively. The grey shaded areas correspond to the period of the last deglaciation from BA to onset of the Holocene (14.7 to $11.6 \mathrm{ka}$ $\mathrm{BP})$. The vertical red dashed lines $(128.5 \mathrm{ka} \mathrm{BP})$ correspond to the onset of the Last Interglacial, following ${ }^{4}$. Left panels: (a) Summer solstice insolation at $65^{\circ} \mathrm{N}^{36}$. (b) Atmospheric $\mathrm{CO}_{2}$ concentrations ${ }^{37}$. (c) Northern Hemisphere ice sheet volume loss rate from two ice sheet reconstructions (grey and red shaded bands ${ }^{4,31}$ ) and a three-dimensional dynamic ice sheet model (bold lines ${ }^{38}$ ). The volume loss rates are calculated from ice sheet volume changes during intervals of 1000 years. (d) Neodymium isotopes of the North Atlantic as a proxy of the relative influences of North Atlantic Deep Water and Antarctic Bottom Water, which is an indicator of the $\mathrm{AMOC}^{9,35}$. (e) Atmospheric $\mathrm{CH}_{4}{ }^{39}$, which reflects abrupt AMOC changes during deglaciations. (f) Antarctic oxygen isotopes at Dome Fuji ${ }^{34}$. (g) Global mean ocean temperature based on noble gases (splined "Mix" of Refs. ${ }^{24,40}$ ). All ice core records are on the AICC2012 age scale. Right panels: (c) Applied freshwater flux in the North Atlantic in two experiments. (d) AMOC, defined as the maximum meridional streamfunction of the AMOC between $30^{\circ} \mathrm{N}$ and $90^{\circ} \mathrm{N}$ and below $500 \mathrm{~m}$ depth. (e) Annual mean 2-m air temperature in Greenland (3-point average of GISP2, NGRIP, and NEEM ice cores). (f) Annual mean 2-m air temperature at Dome Fuji, Antarctica. (g) Global mean ocean temperature. The time series of model results were generated from 20 -year averages. 
(a) T2-like (130ka) - T1-like (9ka)
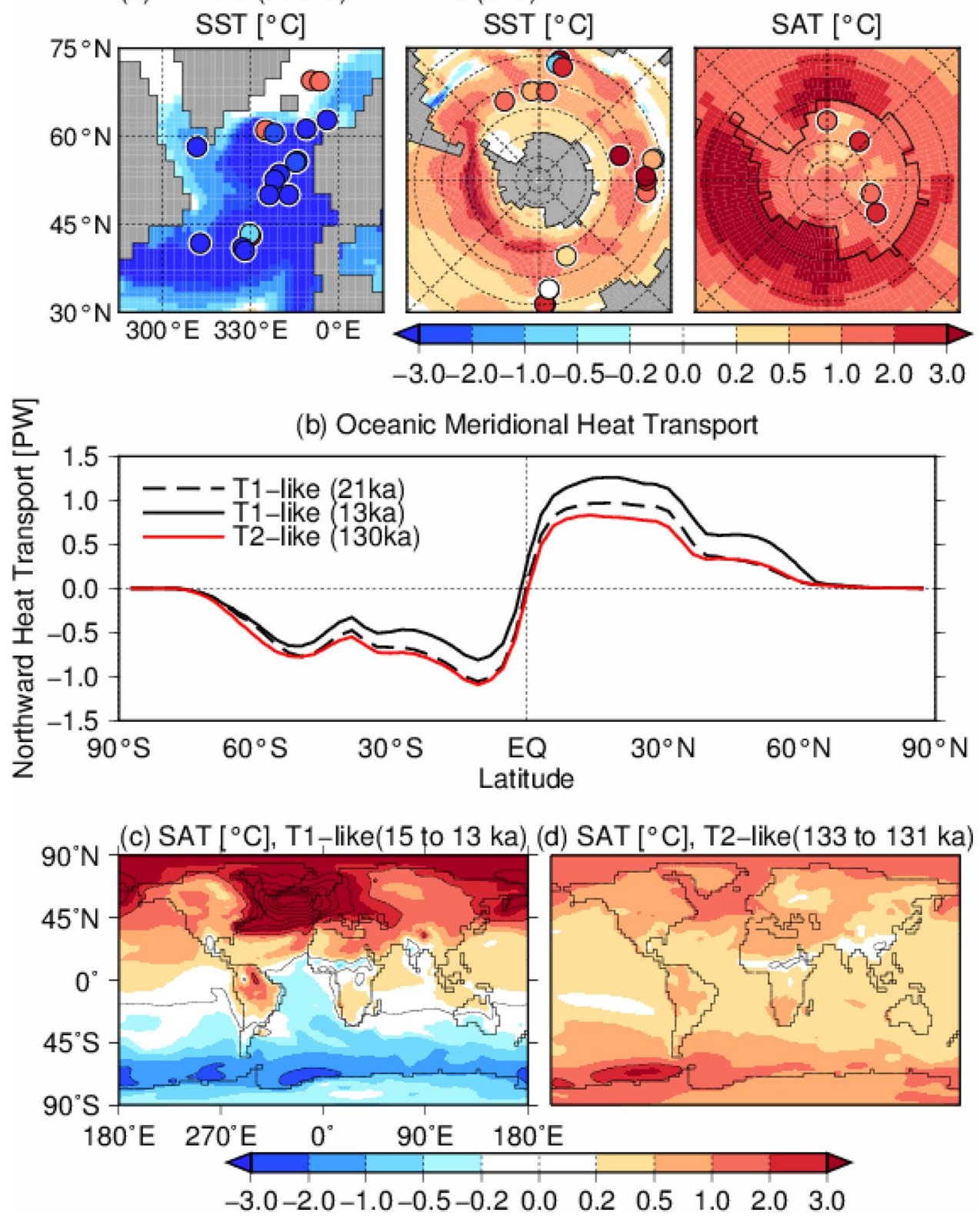

Figure 2. (a) SST and SAT difference between the T2-like experiment at $130 \mathrm{ka} \mathrm{BP}$ in relation to the T1-like experiment at $9 \mathrm{ka}$, corresponding to the Holocene level. The circles represent reconstructions (anomaly of $130 \mathrm{ka} \mathrm{BP}$ relative to the present ${ }^{11}$ ). (b) Simulated oceanic meridional heat transport (positive indicates northward heat transport) at $21 \mathrm{ka}$ and $13 \mathrm{ka}$ in the T1-like experiment and at $130 \mathrm{ka}$ in the T2-like experiment. (c) SAT change during in the T1-like (15-13 ka BP) and T2-like (133-131 ka BP) experiments, corresponding to the Antarctic Cold Reversal of T1. The maps were generated using GMT version 4.5.9 (URL: https://www.soest. hawaii.edu/gmt/).

was fixed to that of the Last Glacial Maximum (LGM). Nevertheless, the results clearly show that the different temporal patterns of warming and cooling trends of the Antarctic SAT and Southern Ocean SST of T1 and T2 can be simulated based only on the difference in meltwater in the North Atlantic.

In Fig. 2a, Antarctic SAT and SST at 130 ka from the T2-like experiment are compared with the reconstruction of $130 \mathrm{ka} \mathrm{BP}$, which corresponds to the early $\mathrm{LIG}^{11}$. The model results in Fig. 2a indicate the temperature anomaly at the early stage of the last interglacial $(130 \mathrm{ka})$, relative to the early Holocene $(9 \mathrm{ka})$. The SAT and SST of the T2-like experiment are characterized by a cooler climate over the Northern Hemisphere and a warmer climate in the Southern Hemisphere (Fig. 2a), and the magnitude of warming in the Southern Ocean and Antarctica is comparable to the reconstructed temperature anomalies during the early LIG. The increase in the AMOC that occurred in the T1-like experiment increased northward heat transport, whereas the heat transport of the T2-like experiment at $130 \mathrm{ka} \mathrm{BP}$ was almost the same as or less than that in the LGM (Fig. 2b). These results indicate 
that the heat accumulated in both hemispheres in the T2-like experiment because of the sustained weak AMOC, whereas the abrupt increase in the AMOC of the T1-like experiment induced bipolar climate changes (Fig. 2c). The SST and subsurface ocean temperature, which are important for the mass balance of ice shelves ${ }^{27,49-52}$, showed a cooling trend and the sea ice extent increased during 15 to $13 \mathrm{ka} \mathrm{BP}$ in the T1-like experiment (Fig. 3). In contrast, there was warming and sea ice retreat in the T2-like experiment; therefore, the warmer Antarctic climate in the T2-like experiment likely contributed to negative mass balance of the Antarctic ice sheet. At the same time, the retreat of sea ice in the T2-like experiment promoted vertical convection in the Southern Ocean and resulted in a greater increase in SST and cooling in the subsurface of the Amundsen Sea, a similar pattern to that reported by Pedro et al. ${ }^{53}$ but in a different ocean basin (Supplementary Fig. S5).

In Supplementary Fig. S6, we present an additional deglaciation experiment using realistic orbital and greenhouse gas forcing of T2. In this experiment, the three orbital parameters (obliquity, eccentricity and perihelion) and greenhouse gas conditions were changed to those of T2 at $138 \mathrm{ka}$ from those in the T1 at $20 \mathrm{ka}$. The meltwater flux was set to the same level of T1 in the early stage of the deglaciation, and it was increased to 0.08 and $0.1 \mathrm{~Sv}$ $\left(10^{6} \mathrm{~m}^{3} / \mathrm{s}\right)$ at 133 and $132 \mathrm{ka}$ respectively; the meltwater flux was at the same level as in the T2-like experiment (Supplementary Fig. S6e). The results show that the abrupt increase in the AMOC occurred before $133 \mathrm{ka}$, but the AMOC returned to a weak mode in response to meltwater, and the weak AMOC remained until the onset of the last interglacial (Supplementary Fig. S6f). In particular, the AMOC oscillated twice during the early stage of T2 (135-133 ka), possibly corresponding to the abrupt climate changes recorded by dust concentrations in an Antarctic ice core from Dome Fuji ${ }^{34}$ or the abrupt changes in the methane record and SSTs in the North Atlantic before $133 \mathrm{ka}^{4,54,55}$. The stronger AMOC in the early stage of the deglaciation was likely because of the orbital parameters and atmospheric $\mathrm{CO}_{2}$ forcing, which tend to warm temperatures over the North Atlantic and the Antarctic region. The most important result in this study was that the Antarctic temperature of T2 was still higher than that of the T1-like experiment (Supplementary Fig. S6g) even if there was an Antarctic cooling event in the early stage of the deglaciation. These results indicate that a weak AMOC during the middle and later stages of the deglaciation was sufficient for the Antarctic warmth of T2. This can be explained by the fact that the typical response time of Antarctic warming to the AMOC is about 1000 to 2000 years $22,48,56,57$.

\section{Results of ice sheet model experiments}

To investigate the possible cause and mechanism of the difference in the meltwater from Northern Hemisphere ice sheets in the later stage between the two glacial terminations, we conducted sensitivity studies using a Northern Hemisphere ice sheet model IcIES-MIROC ${ }^{38}$. Note that the following experiments with this ice sheet model were independent of the climate model deglaciation experiments in this study. In the sensitivity experiment (red line in Fig. 4a, EMOD experiment), the orbital eccentricity was changed to that of the penultimate deglaciation (same period as T2) from the last deglaciation (same period as T1) using the 20 ka ice sheet configurations of the model as an initial condition. In this setting, the larger eccentricity of T2 relative to T1 contributed to greater summer insolation in the Northern Hemisphere and negative mass balance of the ice sheets only after the middle stage of deglaciation (about $17 \mathrm{ka} \mathrm{BP}$ ), as the climatic precession was negative in the early deglaciation (Fig. 4b). The simulated Northern Hemisphere ice sheet volume loss rate was very close to that of the control experiments in the early deglaciation until about $16 \mathrm{ka} \mathrm{BP}$ (Fig. 4c,d). However, significant differences occurred after the middle stage of the deglaciation; the greater orbital eccentricity of the EMOD experiment compared with the control experiment induced greater summer insolation and negative mass balance of the ice sheets after $16 \mathrm{ka} B \mathrm{P}$ (Fig. 4e). The rate of ice sheet volume change was $\sim 1.5$ times larger than that of the control experiment during the period of 15 to $12 \mathrm{ka} \mathrm{BP}$, which corresponds to the BA period of T1. Therefore, the greater orbital eccentricity of T2 compared with T1 had significant influence on the mass balance of Northern Hemisphere ice sheets during the middle and later stages of deglaciation, and also on the meltwater flux caused by volume loss of ice sheets.

\section{Discussion}

The climate model results can be summarized as follows: the middle to late stages of the two deglaciations (133 to $129 \mathrm{ka}$ and 15 to $11 \mathrm{ka}$, grey shaded area in Fig. 1) show a substantial difference in the occurrence of abrupt changes of AMOC and bipolar seesaw climate change because of the meltwater discharge from the Northern Hemisphere ice sheets (by factor of 1.5). Together with previous studies, these results can be explained by the following mechanism. First, the gradual warming of the last two deglaciation tended to strengthen the AMOC as reported by OA2019 ${ }^{28}$, but a relatively small amount of meltwater in the last deglaciation, supported by sea level reconstruction ${ }^{8}$, enabled the AMOC to enter a vigorous mode earlier than the interglacial onset in T1, as in BA warming. Second, the level of meltwater during the latter half of the deglaciation was crucial for Antarctic temperature in T2 and the LIG; it could be higher than in T1 because of a weakened AMOC during the later stage of the deglaciation of T2 (Supplementary Fig. S6g). These results are consistent with a previous study wherein a longer duration of meltwater formation in the deglaciation was found to be needed for Antarctic warming of the LIG ${ }^{22}$. Early AMOC recoveries might not occur as in the reconstructions if meltwater corresponding to Heinrich event 11 is applied ${ }^{8}$. Third, Antarctic warming was interrupted by BA warming and ACR during the later stage of T1, which was critical for a lower Antarctic temperature compared with T2. In our results, Antarctic temperature exhibited a cooling trend for about 2000 years during ACR, as in reconstructions, and the Antarctic warming during the YD event was not sufficient to catch up with the warming exhibited in the T2-like experiment (Fig. 1f). The sustained weak AMOC until the end of deglaciation led to significant Antarctic warming during the onset of the LIG compared with the Holocene, which is consistent with previous modelling studies ${ }^{27,43}$. Thus, our results highlight the importance of transient responses of the climate system dynamics of deglaciation to gradual changes of ice sheet discharge and insolation, associated with AMOC affecting Antarctic warming. 
T1-like, 15 to 13 ka BP
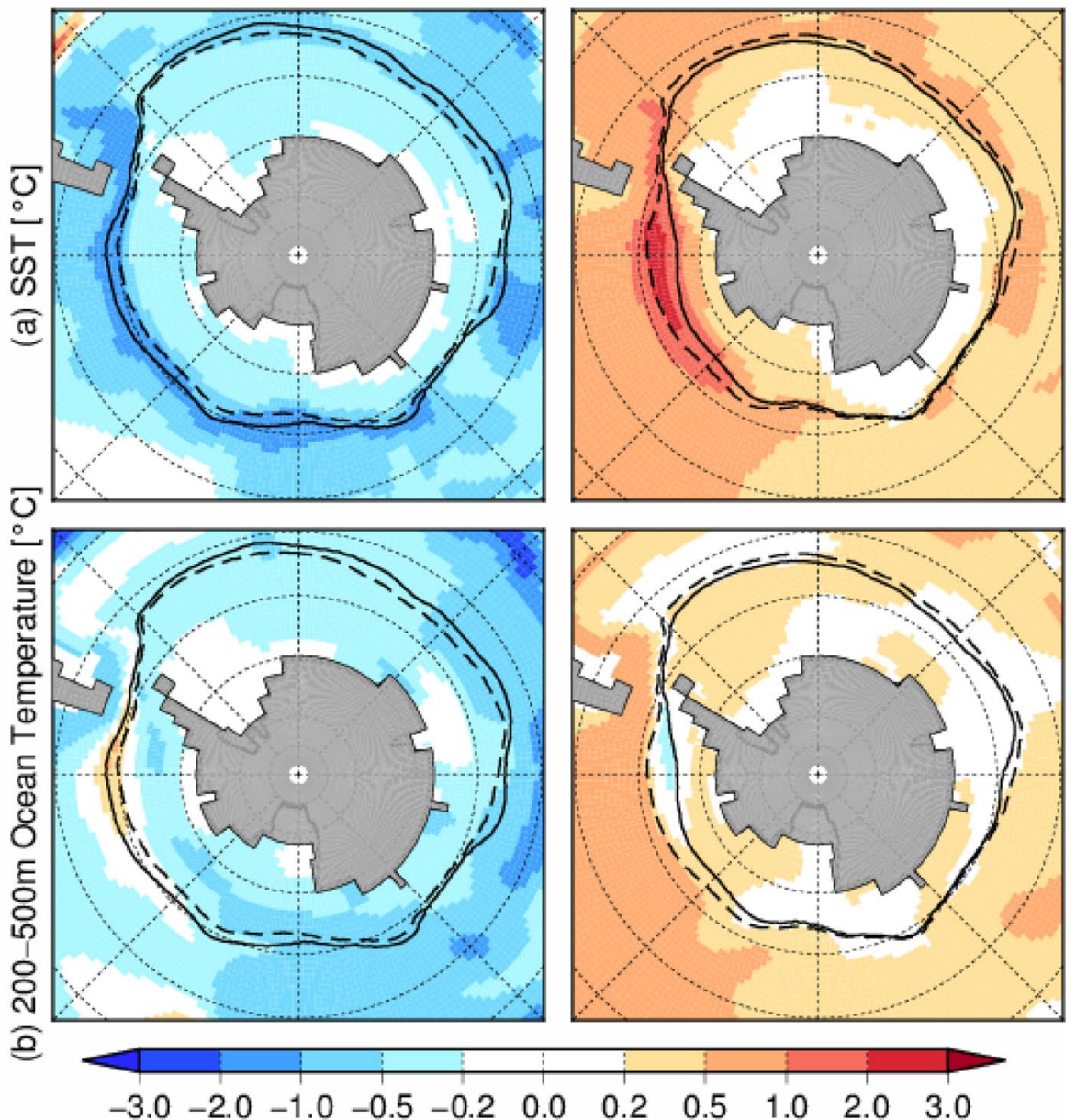

(c) Zonal Mean Ocean Temperature $\left[{ }^{\circ} \mathrm{C}\right]$

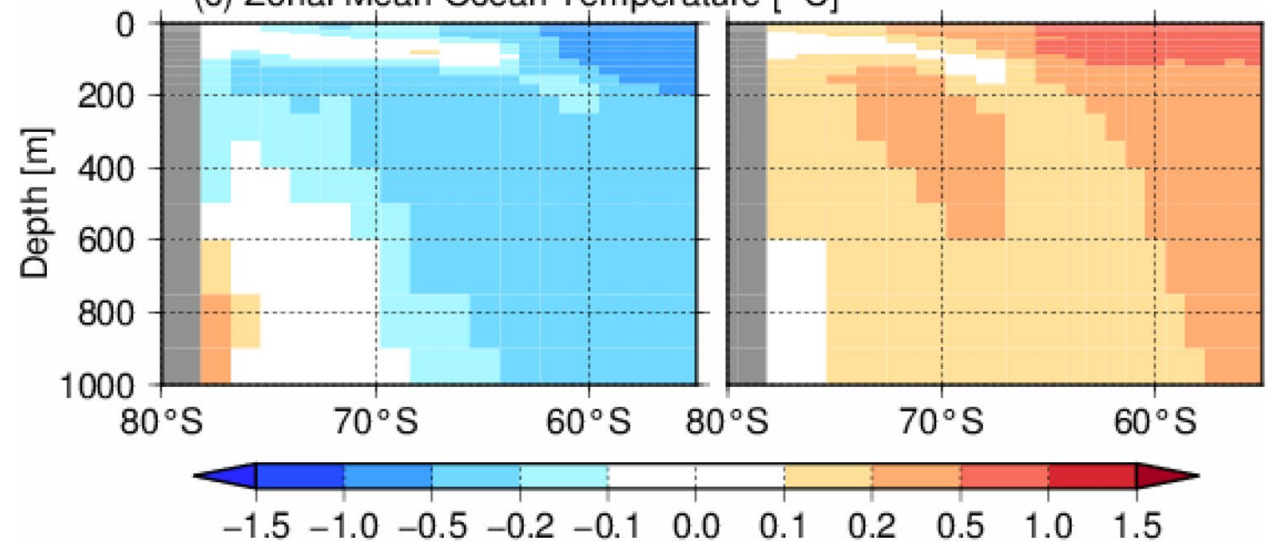

Figure 3. Ocean temperature changes in the T1-like (15-13 ka BP) and T2-like (133-131 ka BP) experiments, corresponding to the Antarctic Cold Reversal of T1. (a,b) SST and subsurface ocean temperature averaged at 200-500 m depth. Dashed and bold lines indicate austral winter sea ice extent, defined by a sea ice concentration of $15 \%$, at 15 and $13 \mathrm{ka}$ (left panels), and 133 and $131 \mathrm{ka}$ (right panels), respectively. (c) Zonal mean ocean temperature averaged for the whole of Antarctica. The maps were generated using GMT version 4.5.9 (URL: https://www.soest.hawaii.edu/gmt/).

Clark et al. ${ }^{27}$ suggested that the larger Eurasian ice sheet during the Penultimate Glacial Maximum (PGM) before $\mathrm{T} 2{ }^{59,60}$ was one primary source of meltwater during the early stage of $\mathrm{T} 2$. The dynamics of marine ice sheets and the extensive Eurasian ice sheet at the PGM were not represented in our ice sheet model, but it is important that the land-based ice sheet alone could be a source of differences after the middle stage of the deglaciation, when 

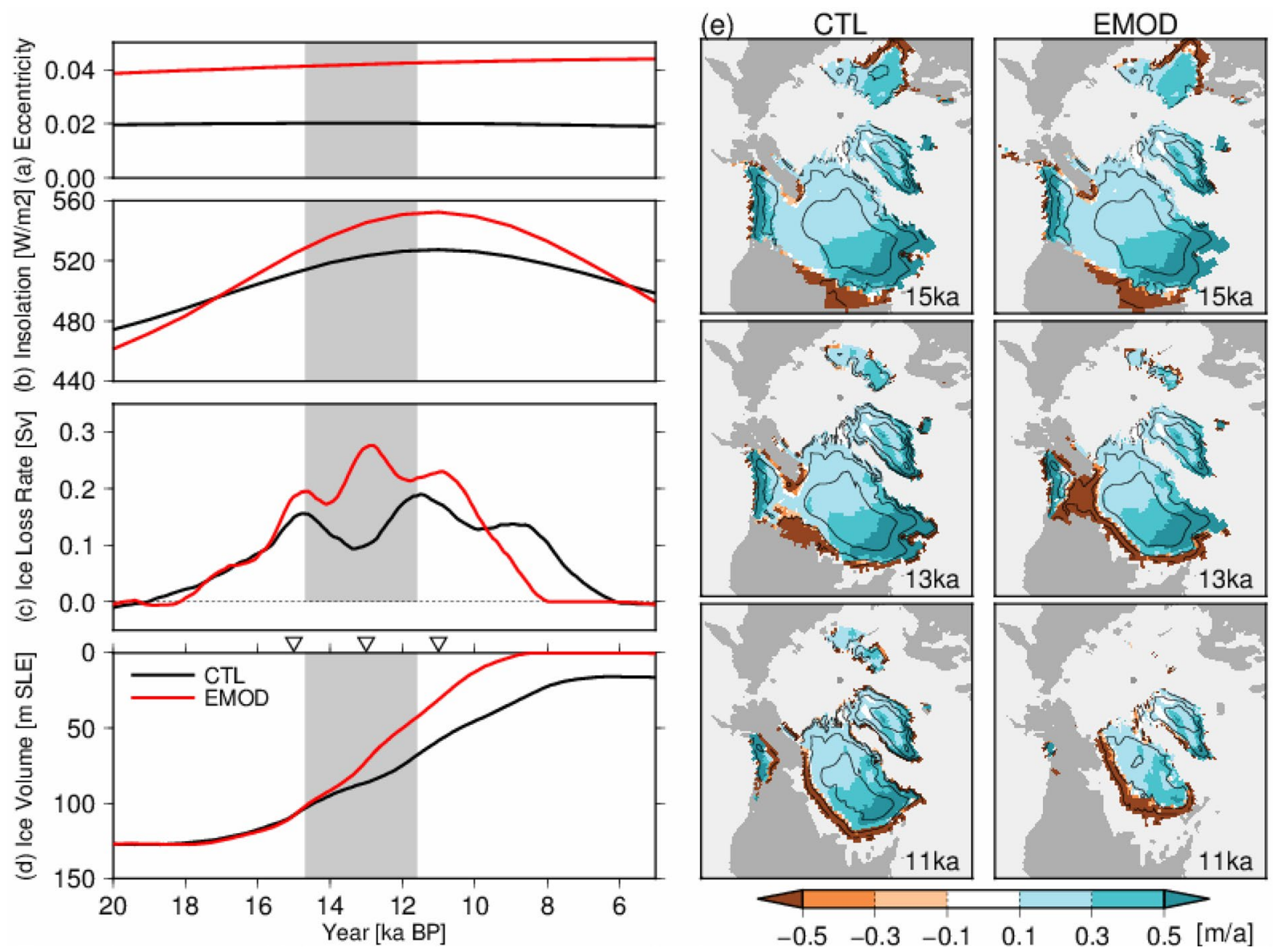

Figure 4. Experimental design and results of the ice sheet model experiments. The black lines indicate the results of simulation of the last 400,000 years ${ }^{38}$. The grey shaded area corresponds to the last deglaciation from the BA period to onset of the Holocene (14.7 to $11.6 \mathrm{ka} \mathrm{BP}$ ), as in Fig. 1. The red lines indicate the experimental design and results of the EMOD (Eccentricity MODified) experiment, where orbital eccentricity was changed to that of T2 at the time of $20 \mathrm{ka} \mathrm{BP}$. (a) Orbital eccentricity and (b) summer solstice insolation at $65^{\circ} \mathrm{N}$ using each eccentricity of (a). (c) Simulated Northern Hemisphere ice loss rate, calculated based on the ice volumes changes in 1000-year intervals. (d) Volume of Northern Hemisphere ice sheets, calculated based on the sum of the North American and Eurasian ice sheets. Here, the volumes of the ice sheets $\left(\mathrm{m}^{3}\right)$ were divided by $4.0 \times 10^{14}$ to determine the sea level equivalent ${ }^{58}$. Triangles show the time slices of (e). (e) Map showing shapes and surface mass balances of ice sheets at three different time slices. Colours indicate the surface mass balance in metres per year. The maps were generated using GMT version 4.5.9 (URL: https://www.soest.hawaii.edu/gmt/).

there were significant differences in the surface mass balances of the ice sheet caused by differences in insolation (Fig. 4). Moreover, the ice sheet model results indicate that the relative importance of the types of forcing could differ between the stages of the deglaciations; the role of orbital eccentricity in mass loss of Northern Hemisphere ice sheets was relatively small in the early stage, whereas it was significant in the middle stage of the deglaciations. In addition, based on the climate model results, a sustained weak AMOC during the middle and later stages was more critical to the peak Antarctic temperature during deglaciation. Even if the AMOC experienced strong modes in the early stage of the deglaciation, possibly corresponding to the observed climate fluctuations ${ }^{54,55}$, Antarctic temperature reached a similar thermal maximum in the late stage of the deglaciation (Supplementary Fig. S6g). Therefore, we propose that in the early stage of T2, the extensive Eurasian ice sheet was an important source of meltwater related to a stronger and longer Heinrich 11 stadial $^{27}$, and that insolation may have been more important in the middle and later stages as a source of meltwater to sustain a weak AMOC during T2, as in reconstructions. In contrast, the climatic consequence of the last deglaciation can be interpreted to be that the smaller eccentricity of T1 could not supply significant meltwater in the North Atlantic and permitted the AMOC to recover as in reconstructions, and that this cooled the Antarctic region, with the WAIS remaining in the present interglacial. Based on the above discussion, we propose that orbital forcing was one important factor in the differences in abrupt climate events of the last two deglaciations, and in the Antarctic warmth of the following interglacials, as discussed in previous studies ${ }^{8,9,23,24}$.

Comparison of the last two deglaciations with climate model experiments provides a unique opportunity to investigate transient responses of the climate system to external forcing, but several climate processes in climate model simulations should be improved in the future. First, the Antarctic ice sheet configuration was fixed to that of the LGM throughout the deglaciation experiments of the climate model, which may have led 
to underestimation of Antarctic surface temperature changes by excluding the effect of changes in the surface elevation ${ }^{19,21}$. The lack of surface elevation changes affected the model-data comparison of surface temperature in the LIG, but it is of importance that the magnitude of Antarctic warming can be simulated with transient climate responses. The Northern Hemisphere ice sheets were also fixed to LGM levels; disintegration of Northern ice sheets would influence the AMOC by changing the air temperature and winds over the North Atlantic ${ }^{61}$. Second, the meltwater in the North Atlantic was not the same as that of the sea level reconstructions or ice sheet model results, and was simplified by applying a specific area over the North Atlantic. We used this simplification to highlight the comparison of the last two deglaciations with different levels of background meltwater, without rapid mass loss of marine ice sheets. This point can be improved further, as complex time series and distributions of meltwater by river runoff have been utilized in the simulation of the last deglaciation ${ }^{25,62,63}$. Third, meltwater influx into the Antarctic Ocean caused by the retreat of the Antarctic ice sheet was not considered; this meltwater could strengthen the stratification of the Southern Ocean and raise the subsurface ocean temperature at intermediate depths ${ }^{26,64,65}$. As shown in the last deglaciation inferred from ice-rafted debris records in the Antarctic Ocean ${ }^{66}$ and ice sheet modelling ${ }^{67,68}$, meltwater would cause greater subsurface ocean temperatures and extensive retreat of the Antarctic ice sheet during T2. In forthcoming future works, transient ice sheets and meltwater from both hemispheres will be included in the deglaciation climate model experiments. Our offline experiments with respective climate model and ice sheet model experiments highlighted the nature of climate system dynamics during deglaciation, but in the future, we plan to test transient simulations with coupled ice sheet-climate models. The LIG has been considered an important constraint of the tipping point of the WAIS ${ }^{69}$; therefore, understanding climate system feedback during deglaciation and interglacial stages is important as it relates to future changes. In particular, global warming and meltwater from the Greenland Ice Sheet weaken the $\mathrm{AMOC}^{70}$. In addition, Antarctic warming induces melting of the Antarctic ice shelves, and meltwater can induce further mass loss of the Antarctic ice sheet ${ }^{71,72}$. We expect that further modelling studies on transient climate-ice sheet interactions will improve our understanding of the climate system and the consequences of climate events in the past, and constrain tipping points and future loss of the Antarctic ice sheet.

\section{Methods}

Climate model. We used the MIROC4m AOGCM, the same model used in the simulation of the last deglaciation (Obase and Abe-Ouchi 2019, hereafter OA2019 ${ }^{28}$ ). The resolution of the atmospheric component was T42 (about $2.8^{\circ} \times 2.8^{\circ}$ ) with 20 vertical levels, and that of the ocean component was about $1.4^{\circ} \times 1^{\circ}$ with 43 vertical levels. MIROC $4 \mathrm{~m}$ produced vigorous AMOC under the LGM when submitted to PMIP2 $2^{73}$. The coefficient of the horizontal isopycnal layer thickness diffusivity of the ocean model was changed to $7.0 \times 10^{6} \mathrm{~cm}^{2} / \mathrm{s} \mathrm{from}$ $3.0 \times 10^{6} \mathrm{~cm}^{2} / \mathrm{s}$, and the present model produces a weak AMOC under the LGM because of enhanced dense Antarctic Bottom Water (AABW) formation ${ }^{34}$. MIROC has been used to investigate the climate of the LGM with radiative forcing and climate feedback ${ }^{74}$, the effect of ice sheets on the climate and the AMOC ${ }^{34,61,75}$, ocean biogeochemical cycles ${ }^{76-78}$, and mass balance of the Antarctic ice shelves ${ }^{79,80}$.

The transient simulations were mostly based on the protocols proposed by the Paleoclimate Modelling Intercomparison Project Phase 4 (PMIP4) for the last and penultimate deglaciations ${ }^{4,31}$. Most of the experimental design of the deglaciation experiments followed OA2019, where the model was initialized with the Last Glacial Maximum (LGM) lasting for more than 30 thousand years ${ }^{34}$, and time-evolving insolation, atmospheric greenhouse gas concentrations, and meltwater were applied based on reconstructions ${ }^{36,37,39,81}$. The continental ice sheets and land-sea mask were fixed to those of the LGM (ICE-5G ${ }^{82}$ ) as used in PMIP2 ${ }^{83}$; therefore, the climate system feedback associated with changes of ice sheets was excluded. Ice sheet reconstructions ${ }^{29,30}$, referred from PMIP $4^{31}$, were used as constraints on meltwater flux in the deglaciation experiments. The meltwater was uniformly applied to $50-70^{\circ} \mathrm{N}$ in the North Atlantic as in previous studies ${ }^{27,84}$. OA2019 showed an increase in the AMOC during BA under a constant meltwater flux of $\sim 0.06 \mathrm{~Sv}$, and the last deglaciation experiment was extended to $9 \mathrm{ka} B P$ to serve as a T1-like experiment covering the YD event and onset of the Holocene. The time series of meltwater flux in the T1-like and T2-like experiments are summarized in Supplementary Table 1. The cumulative glacial meltwater fluxes in the T1-like and T2-like experiments were 28 and $39 \mathrm{~m}$ sea level equivalent at $13 \mathrm{ka} \mathrm{BP}$, and 50 and $74 \mathrm{~m}$ at $10 \mathrm{ka} \mathrm{BP}$, respectively (Supplementary Fig. S1).

Ice sheet model. The ice sheet model with the climate parameterization (IcIES-MIROC) used in this study corresponds to that described by Abe-Ouchi et al. ${ }^{38}$. The horizontal resolution is $1 \times 1$ degrees, and ice sheet dynamics are represented by the Shallow Ice Approximation. The climate factors that control the surface temperature and surface mass balance of ice sheets, such as the lapse rate, albedo feedback and stationary wave feedback, were obtained from a suite of experiments using GCM snapshots to obtain a climate parameterization ${ }^{38,85}$. The surface temperature distribution was parameterized as the sum of the present-day climatology and anomaly due to changes in insolation, atmospheric $\mathrm{CO}_{2}$, ice sheet area, and nonlinear effects estimated from climate model experiments ${ }^{38}$. The surface melt of the ice sheets was calculated with a positive-degree-day method ${ }^{86}$. The Control (CTL) experiment used an experimental design identical to that of Abe-Ouchi et al. ${ }^{38}$; the ice sheet model was initialized with the present-day ice sheet, and was forced by the orbital parameters ${ }^{37}$ and atmospheric $\mathrm{CO}_{2}$ concentration ${ }^{87}$ for the last 400,000 years (Fig. 4a). The simulated total ice sheet volume in the Northern Hemisphere largely reproduced reconstructed sea level change (Fig. 4d, black lines). A sensitivity experiment EMOD (Eccentricity MODified experiment) was performed based on the CTL experiment from 20 to $5 \mathrm{ka}$ BP. In this experiment, the orbital eccentricity was changed to that of the penultimate deglaciation $(133 \mathrm{ka} \mathrm{BP})$ at the time of $20 \mathrm{ka} \mathrm{BP}$, using the $20 \mathrm{ka}$ ice sheet configurations of Abe-Ouchi et al. ${ }^{38}$ as an initial condition. In this setting, the larger eccentricity of T2 relative to T1 contributed to greater summer insolation in the Northern 
Hemisphere and negative mass balance of the ice sheets only after the middle stage of deglaciation (about $17 \mathrm{ka}$ $\mathrm{BP})$, as the climatic precession was negative in the early deglaciation (Fig. 4b).

\section{Data availability}

The presented model data will be available from the repository of the Center for Earth Surface System Dynamics, Atmosphere and Ocean Research Institute, The University of Tokyo (http://cesd.aori.u-tokyo.ac.jp/index_ en.html). Additional data related to this paper may be requested from the authors.

Received: 2 July 2021; Accepted: 21 October 2021

Published online: 25 November 2021

\section{References}

1. Kawamura, K. et al. Northern Hemisphere forcing of climatic Cycles in Antarctica over the past 360,000 years. Nature 448(August), 912-916. https://doi.org/10.1038/nature06015 (2007).

2. Clark, et al. Global climate evolution during the last deglaciation. Proc. Natl. Acad. Sci. U.S.A. 109(19), 1134-1142. https://doi. org/10.1073/pnas.1116619109 (2012).

3. Denton, G. H. et al. The last glacial termination. Science 328, 1652-1656. https://doi.org/10.1126/science.1184119 (2010).

4. Menviel, L. et al. The penultimate deglaciation: Protocol for Paleoclimate Modelling Intercomparison Project (PMIP) phase 4 transient numerical simulations between 140 and $127 \mathrm{ka}$, version 1.0. Geosci. Model Dev. 12(8), 3649-3685. https://doi.org/10. 5194/gmd-12-3649-2019 (2019).

5. McManus, J. F., Francois, R., Gherardi, J--M., Keigwin, L. D. \& Brown-Leger, S. Collapse and rapid resumption of Atlantic meridional circulation linked to deglacial climate changes. Nature 428(6985), 834-837. https://doi.org/10.1038/nature02494 (2004).

6. Shakun, J. D. et al. Global warming preceded by increasing carbon dioxide concentrations during the last deglaciation. Nature 484, 49-54. https://doi.org/10.1038/nature10915 (2012).

7. Cheng, H. et al. Ice age terminations. Science 326(5950), 248-252. https://doi.org/10.1126/science.1177840 (2009).

8. Marino, G. et al. Bipolar seesaw control on last interglacial sea level. Nature 522, 197-201. https://doi.org/10.1038/nature14499 (2015).

9. Deaney, E. L., Barker, S. \& van de Flierdt, T. Timing and nature of AMOC recovery across Termination 2 and magnitude of deglacial $\mathrm{CO}_{2}$ change. Nat. Commun. https://doi.org/10.1038/ncomms14595 (2017).

10. Otto-Bliesner, B. L. et al. Large-scale features of Last Interglacial climate: Results from evaluating the lig127k simulations for the Coupled Model Intercomparison Project (CMIP6)-Paleoclimate Modeling Intercomparison Project (PMIP4). Clim. Past 17, 63-94. https://doi.org/10.5194/cp-17-63-2021 (2021).

11. Capron, E., Govin, A., Feng, R., Otto-Bliesner, B. L. \& Wolff, E. W. Critical evaluation of climate syntheses to benchmark CMIP6/ PMIP4 127 ka Last Interglacial simulations in the high-latitude regions. Quat. Sci. Rev. 168, 137-150. https://doi.org/10.1016/j. quascirev.2017.04.019 (2017).

12. Waelbrocke, C. et al. Sea-level and deep water temperature changes derived from benthic foraminifera isotopic records. Quat. Sci. Rev. 21(1-3), 295-305. https://doi.org/10.1016/S0277-3791(01)00101-9 (2002).

13. Kopp, R. E., Simons, F. J., Mitrovica, J. X., Maloof, A. C. \& Oppenheimer, M. Probabilistic assessment of sea level during the last interglacial stage. Nature 462, 863-867. https://doi.org/10.1038/nature08686 (2009).

14. Dutton, A. \& Lambeck, K. Ice volume and sea level during the last interglacial. Science 337, 216-219. https://doi.org/10.1126/scien ce.1205749 (2012).

15. Dutton, A. et al. Sea-level rise due to polar ice-sheet mass loss during past warm periods. Science https://doi.org/10.1126/science. aaa4019 (2015).

16. Turney, C. S. M. et al. Early Last Interglacial ocean warming drove substantial ice mass loss from Antarctica. Proc. Natl. Acad. Sci. 117(8), 3996-4006. https://doi.org/10.1073/pnas.1902469117 (2020).

17. Capron, E. et al. Temporal and spatial structure of multi-millennial temperature changes at high latitudes during the Last Interglacial. Quat. Sci. Rev. 103, 116-133. https://doi.org/10.1016/j.quascirev.2014.08.018 (2014).

18. Govin, A. et al. Sequence of events from the onset to the demise of the Last Interglacial: Evaluating strengths and limitations of chronologies used in climatic archives. Quat. Sci. Rev. 129, 1-36. https://doi.org/10.1016/j.quascirev.2015.09.018 (2015).

19. Holden, P. B. et al. Interhemispheric coupling, the West Antarctic Ice Sheet and warm Antarctic interglacials. Clim. Past 6, 431-443. https://doi.org/10.5194/cp-6-431-2010 (2010).

20. Loutre, M. F. et al. Factors controlling the last interglacial climate as simulated by LOVECLIM1.3. Clim. Past 10, 1541-1565. https:// doi.org/10.5194/cp-10-1541-2014 (2014).

21. Stone, E. J. et al. Impact of meltwater on high-latitude early Last Interglacial climate. Clim. Past 12, 1919-1932. https://doi.org/10. 5194/cp-12-1919-2016 (2016).

22. Holloway, M. D., Sime, L. C., Singarayer, J. S., Tindall, J. C. \& Valdes, P. J. Simulating the 128 -ka Antarctic climate response to Northern Hemisphere ice sheet melting using the isotope-enabled HadCM3. Geophys. Res. Lett. 45, 11921-11929. https://doi.org/ $10.1029 / 2018$ GL079647 (2018).

23. Carlson, A. E. Why there was not a Younger Dryas-like event during the penultimate Deglaciation. Quat. Sci. Rev. $27,882-887$. https://doi.org/10.1016/j.quascirev.2008.02.004 (2008).

24. Shackleton, S. et al. Global ocean heat content in the Last Interglacial. Nat. Geosci. 13, 77-81. https://doi.org/10.1038/s41561-0190498-0 (2020).

25. Liu, Z. et al. Transient simulation of last deglaciation with a new mechanism for Bolling-Allerod warming. Science 325(5938), 310-314. https://doi.org/10.1126/science.1171041 (2009).

26. Menviel, L., Timmermann, A., Timm, O. E. \& Mouchet, A. Deconstructing the Last Glacial termination: The role of millennial and orbital-scale forcings. Quat. Sci. Rev. 30(9-10), 1155-1172. https://doi.org/10.1016/j.quascirev.2011.02.005 (2011).

27. Clark, P. U. et al. Oceanic forcing of penultimate deglacial and last interglacial sea-level rise. Nature 577, 660-664. https://doi.org/ 10.1038/s41586-020-1931-7 (2020).

28. Obase, T. \& Abe-Ouchi, A. Abrupt Bolling-Allerod warming simulated under gradual forcing of the last deglaciation. Geophys. Res. Lett. https://doi.org/10.1029/2019GL084675 (2019).

29. Peltier, W. R., Argus, D. F. \& Drummond, R. Space geodesy constrains ice age terminal deglaciation: The global ICE-6G_C (VM5a) model. J. Geophys. Res. Solid Earth 120, 450-487. https://doi.org/10.1002/2014JB011176 (2015).

30. Tarasov, L., Dyke, A. S., Neal, R. M. \& Peltier, W. R. A data-calibrated distribution of deglacial chronologies for the North American ice complex from glaciological modeling, Earth Planet. Sci. Lett. 315-316, 30-40. https://doi.org/10.1016/j.epsl.2011.09.010 (2012).

31. Ivanovic, R. F. et al. Transient climate simulations of the deglaciation 21-9 thousand years before present (version 1) - PMIP4 Core experiment design and boundary conditions. Geosci. Model Dev. 9, 2563-2587. https://doi.org/10.5194/gmd-9-2563-2016 (2016).

32. Grant, K. et al. Sea-level variability over five glacial cycles. Nat. Commun. 5, 5076. https://doi.org/10.1038/ncomms6076 (2014). 
33. Risebrobakken, B. et al. Inception of the Northern European ice sheet due to contrasting ocean and insolation forcing. Quat. Res. 67, 128-135. https://doi.org/10.1016/j.yqres.2006.07.007 (2007).

34. Kawamura, K. et al. State dependence of climatic instability over the past 720,000 years from Antarctic ice cores and climate modeling. Sci. Adv. https://doi.org/10.1126/sciadv.1600446 (2017).

35. Roberts, N. L., Piotrowski, A. M., McManus, J. F. \& Keigwin, L. D. Synchronous deglacial overturning and water mass source changes. Science 327(5961), 75-78. https://doi.org/10.1126/science.1178068 (2010).

36. Berger, A. \& Loutre, M. F. Insolation values for the climate of the last 10 million years. Quat. Sci. Rev. 10(4), 297-317 (1991).

37. Bereiter, B. et al. Revision of the EPICA Dome $\mathrm{C} \mathrm{CO}_{2}$ record from 800 to $600 \mathrm{kyr}$ before present. Geophys. Res. Lett. 42, 542-549. https://doi.org/10.1002/2014GL061957 (2015).

38. Abe-Ouchi, A. et al. Insolation-driven 100,000-year glacial cycles and hysteresis of ice-sheet volume. Nature 500, 190-193. https:// doi.org/10.1038/nature12374 (2013).

39. Loulergue, L. et al. Orbital and millennial-scale features of atmospheric $\mathrm{CH}_{4}$ over the past 800,000 years. Nature 453(7193), 383-386. https://doi.org/10.1038/nature06950 (2008).

40. Bereiter, B., Shackleton, S., Baggenstos, D., Kawamura, K. \& Severinghaus, J. Mean global ocean temperatures during the last glacial termination. Nature 553, 39-44. https://doi.org/10.1038/nature25152 (2018).

41. Knorr, G. \& Lohmann, G. Southern Ocean origin for the resumption of Atlantic thermohaline circulation during deglaciation. Nature 424, 532-536. https://doi.org/10.1038/nature01855 (2003).

42. Knorr, G. \& Lohmann, G. Rapid transitions in the Atlantic thermohaline circulation triggered by global warming and meltwater during the last deglaciation. Geochem. Geophys. Geosyst. 8, Q12006. https://doi.org/10.1029/2007GC001604 (2007).

43. Ganopolski, A. \& Roche, D. M. On the nature of lead-lag relationships during glacial-interglacial climate transitions. Quat. Sci. Rev. 28, 3361-3378. https://doi.org/10.1016/j.quascirev.2009.09.019 (2009).

44. Zhang, X., Knorr, G., Lohmann, G. \& Barker, S. Abrupt North Atlantic circulation changes in response to gradual $\mathrm{CO}_{2}$ forcing in a glacial climate state. Nat. Geosci. 10, 518-523. https://doi.org/10.1038/NGEO2974 (2017).

45. Lowry, D. P., Golledge, N. R., Menviel, L. \& Bertler, N. A. N. Deglacial evolution of regional Antarctic climate and Southern Ocean conditions in transient climate simulations. Clim. Past 15, 189-215. https://doi.org/10.5194/cp-15-189-2019 (2019).

46. Ritz, S. P., Stocker, T. F. \& Severinghaus, J. P. Noble gases as proxies of mean ocean temperature: Sensitivity studies using a climate model of reduced complexity. Quat. Sci. Rev. 30, 3728-3741. https://doi.org/10.1016/j.quascirev.2011.09.021 (2011).

47. Galbraith, E. D., Merlis, T. M. \& Palter, J. B. Destabilization of glacial climate by the radiative impact of Atlantic Meridional Overturning Circulation disruptions. Geophys. Res. Lett. 43, 8214-8221. https://doi.org/10.1002/2016GL069846 (2016).

48. Pedro, J. B. et al. Beyond the bipolar seesaw: Toward a process understanding of interhemispheric coupling. Quat. Sci. Rev. 192, 27-46. https://doi.org/10.1016/j.quascirev.2018.05.005 (2018).

49. Pollard, D. \& DeConto, R. M. Modelling West Antarctic ice sheet growth and collapse through the past five million years. Nature 458, 329-332. https://doi.org/10.1038/nature07809 (2009).

50. Sutter, J., Gierz, P., Grosfeld, K., Thoma, M. \& Lohmann, G. Ocean temperature thresholds for Last Interglacial West Antarctic Ice Sheet collapse. Geophys. Res. Lett. https://doi.org/10.1002/2016GL067818 (2016).

51. Deconto, R. M. \& Pollard, D. Contribution of Antarctica to past and future sea-level rise. Nature 531(7596), 591-597. https://doi. org/10.1038/nature17145 (2016).

52. Golledge, N. R., Levy, R. H., McKay, R. M. \& Naish, T. R. East Antarctic ice sheet most vulnerable to Weddell Sea warming. Geophys. Res. Lett. https://doi.org/10.1002/2016GL072422 (2017).

53. Pedro, J. B. et al. Southern Ocean deep convection as a driver of Antarctic warming events. Geophys. Res. Lett. https://doi.org/10. 1002/2016GL067861 (2016).

54. Tzedakis, P. C. et al. Enhanced climate instability in the North Atlantic and southern Europe during the Last Interglacial. Nat. Commun. 9, 4235. https://doi.org/10.1038/s41467-018-06683-3 (2018).

55. Domínguez-Villar, D. et al. Millennial climate oscillations controlled the structure and evolution of Termination II. Sci. Rep. 10, 14912. https://doi.org/10.1038/s41598-020-72121-4 (2020).

56. Capron, E. et al. Millennial and sub-millennial scale climatic variations recorded in polar ice cores over the last glacial period. Clim. Past 6, 345-365. https://doi.org/10.5194/cp-6-345-2010 (2010).

57. WAIS Divide Project Members. Precise interpolar phasing of abrupt climate change during the last ice age. Nature 520, 661-665. https://doi.org/10.1038/nature14401 (2015).

58. Allison, I., Barry, R. G. \& Goodison, B., eds. Climate and Cryosphere (CLiC) Project. Science and Co-ordination Plan, Version 1. Geneva, World Meteorological Organization. World Climate Research Programme. (WCRP-114, WMO/TD 1053) (2001).

59. Lambeck, K., Purcell, A., Funder, S., Kjar, K. H., Larsen, E. \& Moller, P. Constraints on the Late Saalian to early Middle Weichselian ice sheet of Eurasia from field data and rebound modelling. Boreas. 35, 539-575. Oslo. ISSN 0300-9483 (2006).

60. Colleoni, F. N., Kirchner, F., Niessen, A. Q. \& Liakka, J. An East Siberian ice shelf during the Late Pleistocene glaciations: Numerical reconstructions. Quat. Sci. Rev. 147(1), 148-163. https://doi.org/10.1016/j.quascirev.2015.12.023 (2016).

61. Sherriff-Tadano, S., Abe-Ouchi, A., Yoshimori, M., Oka, A. \& Chan, W. Influence of glacial ice sheets on the Atlantic meridional overturning circulation through surface wind change. Clim. Dyn. https://doi.org/10.1007/s00382-017-3780-0 (2018).

62. Bethke, I., Li, C. \& Nisancioglu, K. H. Can we use ice sheet reconstructions to constrain meltwater for deglacial simulations?. Paleoceanography 27, PA2205. https://doi.org/10.1029/2011PA002258 (2012).

63. Ivanovic, R. F., Gregoire, L. J., Wickert, A. D., Valdes, P. J. \& Burke, A. Collapse of the North American ice saddle 14,500 years ago caused widespread cooling and reduced ocean overturning circulation. Geophys. Res. Lett. https://doi.org/10.1002/2016GL0718 49 (2016).

64. Stouffer, R. J., Seidov, D. \& Haupt, B. J. Climate response to external sources of freshwater: North Atlantic versus the Southern Ocean. J. Clim. 20, 436-448. https://doi.org/10.1175/JCLI4015.1 (2007).

65. Phipps, S. J., Fogwill, C. J. \& Turney, C. S. M. Impacts of marine instability across the East Antarctic Ice Sheet on Southern Ocean dynamics. Cryosphere 10, 2317-2328. https://doi.org/10.5194/tc-10-2317-2016 (2016).

66. Weber, M. E. et al. Millennial-scale variability in Antarctic ice-sheet discharge during the last deglaciation. Nature 510, 134-138. https://doi.org/10.1038/nature13397 (2014).

67. Golledge, N. R. et al. Antarctic contribution to meltwater pulse 1A from reduced Southern Ocean overturning. Nat. Commun. 5, 1-10. https://doi.org/10.1038/ncomms6107 (2014).

68. Fogwill, C. J. et al. Antarctic ice sheet discharge driven by atmosphere-ocean feedbacks at the Last Glacial Termination. Sci. Rep. 7, 1-10. https://doi.org/10.1038/srep39979 (2017).

69. Fischer, et al. Palaeoclimate constraints on the impact of $2{ }^{\circ} \mathrm{C}$ anthropogenic warming and beyond. Nat. Geosci. 11, 474-485. https://doi.org/10.1038/s41561-018-0146-0 (2018).

70. Bakker, P. et al. Fate of the Atlantic Meridional Overturning Circulation: Strong decline under continued warming and Greenland melting. Geophys. Res. Lett. 43(23), 12252-12260. https://doi.org/10.1002/2016GL070457 (2016).

71. Hellmer, H. H., Kauker, F., Timmermann, R. \& Hattermann, T. The fate of the Southern Weddell sea continental shelf in a warming climate. J. Clim. 30(12), 4337-4350. https://doi.org/10.1175/JCLI-D-16-0420.1 (2017).

72. Golledge, N. R. et al. Global environmental consequences of twenty-first-century ice-sheet melt. Nature 566(7742), 65-72. https:// doi.org/10.1038/s41586-019-0889-9 (2019). 
73. Otto-Bliesener, B. L. et al. Last Glacial Maximum ocean thermohaline circulation: PMIP2 model intercomparisons and data constraints. Geophys. Res. Lett. 34(12), L12706. https://doi.org/10.1029/2007GL029475 (2007).

74. Yoshimori, M., Yokohata, T. \& Abe-Ouchi, A. A comparison of climate feedback strength between $\mathrm{CO}_{2}$ doubling and LGM experiments. J. Clim. 22, 3374-3395. https://doi.org/10.1175/2009JCLI2801.1 (2009).

75. Abe-Ouchi, A. et al. Ice-sheet configuration in the CMIP5/PMIP3 Last Glacial Maximum experiments. Geosci. Model Dev. 8(11), 3621-3637. https://doi.org/10.5194/gmd-8-3621-2015 (2015).

76. Kobayashi, H., Abe-Ouchi, A. \& Oka, A. Role of Southern Ocean stratification in glacial atmospheric $\mathrm{CO}_{2}$ reduction evaluated by a three-dimensional ocean general circulation model. Paleoceanography 30, 1202-1216. https://doi.org/10.1002/2015PA002786 (2015).

77. Kobayashi, H. \& Oka, A. Response of atmospheric $\mathrm{pCO}_{2}$ to glacial changes in the Southern Ocean amplified by carbonate compensation. Paleoceanogr. Paleoclimatol. 33(11), 1206-1229. https://doi.org/10.1029/2018PA003360 (2018).

78. Yamamoto, A., Abe-Ouchi, A., Ohgaito, R., Ito, A. \& Oka, A. Glacial $\mathrm{CO}_{2}$ decrease and deep-water deoxygenation by iron fertilization from glaciogenic dust. Clim. Past 15, 981-996. https://doi.org/10.5194/cp-15-981-2019 (2019).

79. Kusahara, K. et al. Modelling the Antarctic marine cryosphere at the last glacial maximum. Ann. Glaciol. 56(69), 425-435 (2015).

80. Obase, T., Abe-Ouchi, A., Kusahara, K., Hasumi, H. \& Ohgaito, R. Responses of basal melting of Antarctic ice shelves to the climatic forcing of the Last Glacial Maximum and $\mathrm{CO}_{2}$ doubling. J. Clim. 30(10), 3473-3497. https://doi.org/10.1175/JCLI-D-15.0908.1 (2017).

81. Schilt, A. et al. Atmospheric nitrous oxide during the last 140,000 years. Earth Planet. Sci. Lett. 300, 33-43. https://doi.org/10. 1016/j.epsl.2010.09.027 (2010).

82. Peltier, W. R. Global glacial isostasy and the surface of the ice-age earth: The Ice-5g(Vm2) model and grace. Annu. Rev. Earth Planet. Sci. 32, 111-149 (2004).

83. Braconnot, P. et al. Results of PMIP2 coupled simulations of the mid-Holocene and last glacial maximum-Part 1: Experiments and large-scale features. Clim. Past 3(2), 261-277. https://doi.org/10.5194/cp-3-261-2007 (2007).

84. Kageyama, M. et al. Climatic impacts of fresh water hosing under Last Glacial Maximum conditions: A multi-model study. Clim. Past 9, 935-953. https://doi.org/10.5194/cp-9-935-2013 (2013).

85. Abe-Ouchi, A., Segawa, T. \& Saito, F. Climatic conditions for modelling the Northern Hemisphere ice sheets throughout the ice age cycle. Clim. Past. 3, 423-438. https://doi.org/10.5194/cpd-3-301-2007 (2007).

86. Reeh, N. Parameterization of melt rate and surface temperature on the Greenland ice sheet. Polarforschung 59, 113-128 (1991).

87. Petit, J. R. et al. Climate and atmospheric history of the past 420,000 years from the Vostok ice core, Antarctica. Nature 399, 429-436 (1999).

\section{Acknowledgements}

This research was supported by JSPS KAKENHI Grants 17H06104, 17H06323 and JPJSBP120213203. We performed numerical simulations on the Earth Simulator 3 at Japan Agency for Marine-Earth Science and Technology (JAMSTEC). We thank Sara J. Mason, M.Sc., from Edanz Group (https://jp.edanz.com/ac) for editing the English text of a draft of this manuscript.

\section{Author contributions}

All authors conceived the study. T. O. and A. A-O designed and performed the climate model simulation, analysed the results. T. O., A. A-O., and F. S. designed and performed the ice sheet model simulation, and analysed the results. The manuscript was written by T. O. with contributions from all authors.

\section{Competing interests}

The authors declare no competing interests.

\section{Additional information}

Supplementary Information The online version contains supplementary material available at https://doi.org/ 10.1038/s41598-021-01651-2.

Correspondence and requests for materials should be addressed to T.O.

Reprints and permissions information is available at www.nature.com/reprints.

Publisher's note Springer Nature remains neutral with regard to jurisdictional claims in published maps and institutional affiliations.

Open Access This article is licensed under a Creative Commons Attribution 4.0 International License, which permits use, sharing, adaptation, distribution and reproduction in any medium or format, as long as you give appropriate credit to the original author(s) and the source, provide a link to the Creative Commons licence, and indicate if changes were made. The images or other third party material in this article are included in the article's Creative Commons licence, unless indicated otherwise in a credit line to the material. If material is not included in the article's Creative Commons licence and your intended use is not permitted by statutory regulation or exceeds the permitted use, you will need to obtain permission directly from the copyright holder. To view a copy of this licence, visit http://creativecommons.org/licenses/by/4.0/.

(C) The Author(s) 2021 